\title{
A longitudinal investigation of older adults' physical activity: Testing an integrated dual-process model
}

\author{
Urska Arnautovska ${ }^{1}$, Lena Fleig ${ }^{2}$, Frances O’Callaghan ${ }^{1}$ and Kyra Hamilton ${ }^{1,3}$
}

${ }^{1}$ School of Applied Psychology and Menzies Health Institute Queensland, Griffith University, Brisbane, Australia

${ }^{2}$ Health Psychology, Freie Universität Berlin, Germany

${ }^{3}$ School of Psychology and Speech Pathology and Health Psychology and Behavioural Medicine Research Group, Curtin University, Perth, Western Australia

Suggested citation: Arnautovska, U., Fleig, L., O’Callaghan, F. \& Hamilton, K. (2017). A longitudinal investigation of older adults' physical activity: Testing an integrated dual-process model. Psychology \& Health, 32(2). 166-185.

Corresponding author: Urska Arnautovska, Griffith University, Building M24 Psychology, 176 Messines Ridge Road, Mt Gravatt 4122, Australia. Email:

urska.arnautovska@griffithuni.edu.au 


\title{
A longitudinal investigation of older adults' physical activity: Testing an integrated dual-process model
}

\begin{abstract}
Objective: To assess the effects of conscious and non-conscious processes for prediction of older adults' physical activity, we tested a dual-process model that integrated motivational (behavioural intention) and volitional (action planning and coping planning) processes with non-conscious, automatic processes (habit). Method: Participants $(N=215)$ comprised community-dwelling older adults $(M=73.8$ years $)$. A longitudinal design was adopted to investigate direct and indirect effects of intentions, habit strength (Time 1), and action planning and coping planning (Time 2) on physical activity behaviour (Time 3). Structural equation modelling was used to evaluate the model. Results: The model provided a good fit to the data, accounting for $44 \%$ of the variance in physical activity behaviour at Time 3 . Physical activity was predicted by intentions, action planning, and habit strength, with action planning mediating the intention-behaviour relationship. An effect of sex was also found where males used fewer planning strategies and engaged in more physical activity than females. Conclusions: By investigating an integration of conscious and non-conscious processes, this study provides a novel understanding of older adults' physical activity. Interventions aiming to promote physical activity behaviour of older adults should target the combination of psychological processes.
\end{abstract}

Key words: physical activity; older adults; intention-behaviour gap; dual-process model; theory integration; habit; planning 


\section{Introduction}

Strong empirical evidence suggests individuals' intentions to achieve a desired goal, such as engagement in regular physical activity (PA), which is associated with a range of health benefits (Rezende, Rey-López, Matsudo, \& do Luiz, 2014), predict subsequent behaviour (Sheeran, 2002; McEachan, Conner, Taylor, \& Lawton, 2011). However, there is also substantial research investigating the intention-behaviour gap, reflecting the fact that people do not always achieve what they intented to do (Sheeran, 2002; Sheeran \& Webb, 2016). In fact, research shows that $46 \%$ of individuals who are motivated to engage in PA do not realise their intentions (Rhodes \& de Bruijn, 2013), a phenomenon known as inclined abstainers (Orbell \& Sheeran, 1998). Advancing our understanding of psychological processes involved in individuals' decision making within the context of PA in older adults seems a particularly useful and timely line of investigation since older adults are at risk for low levels of physical activity (Smith, Gardner, Fisher, \& Hamer, 2015), sedentary behaviour (e.g., Fleig, McAllister, Brsher, et al., 2016), and associated morbidity (Rezende, 2014). Indeed, Ziegelmann and Knoll (2015) specifically argued for the need to consider multiple theoretical perspectives when understanding health-related behaviours such as PA in older adults. Integration of theories that propose alternative and/or complementary processes guiding health behaviour may offer a means of advancing theory towards a more comprehensive understanding of behaviour (Conner, 2015; Hagger, 2009).

Latest research (Allom, Mullan, Cowie, \& Hamilton, 2016; Hagger, \& Chatzisarantis, 2014; Mullan, Henderson, Kothe, Allom, Orbell, \& Hamilton, 2016; Presseau et al., 2014) supports using a dual-process approach that integrates both conscious, reflective processes and non-conscious, automatic processes in decision making and provides evidence for the importance of investigating motivational processes (e.g., behavioural intention), volitional processes (e.g., planning), and automatic processes (e.g., habit) on behaviour. Despite 
emerging research using more integrated approaches to better understand human behaviour, an evidence base focused on understanding the effects of multiple processes on behaviour is lacking (Hagger \& Chatzisarantis, 2014). Within the context of the current study, such evidence would help to explain why older adults may be motivated to ensure they engage in a healthy lifestyle yet corresponding intentions and behaviours do not materialise. To assess the effects of conscious and non-conscious processes for prediction of older adults' PA, the aim of the current study was to test a dual-process model that integrated motivational and volitional processes with automatic processes.

\section{Conscious, Reflective Processes}

Among the major theories that have been applied to the understanding of social and health behaviour, intention is assumed to be the most proximal predictor of behaviour. The theory of planned behaviour (TPB; Ajzen, 1991), given intention is central to the model, is perhaps the most widely used social-cognitive theory of behaviour. Intention is defined as a motivational concept which prompts an individual to engage in a specific behaviour and determines the direction and intensity of one's goal-directed actions (Gollwitzer, 1993). While research supports the key role of intentions for behavioural enactment (Hagger, Chatzisarantis, \& Biddle, 2002; McEachan, Conner, Taylor, \& Lawton, 2011), review studies have shown that a substantial amount of variance between intentions and behaviour remains unexplained (Rhodes \& de Bruijn, 2013; Sheeran, 2002). This limitation of intentions translating to behaviour, known as the intention-behaviour gap (Sheeran, 2002, 2016), prompted the development of alternative theoretical perspectives to try to explain individuals' behaviour, differentiating between a motivational phase (i.e., goal-setting stage) and volitional phase (i.e., goal-pursuit phase) when it comes to understanding motivated action. This is because behavioural decision making cannot be viewed in a unidimensional fashion and motivational 
processes in isolation are unlikely to change behaviour; thus, other factors are more likely to be influential in the self-regulation process and subsequent pursuit of an action.

The factors proposed to bridge the intention-behaviour gap include different types of planning techniques, which originate in Gollwitzer's (1993) concept of implementation intentions. Planning constructs are key to the health action process approach (HAPA; Schwarzer, 2008; Schwarzer \& Luszczynska, 2008), which suggests that the adoption, initiation, and maintenance of health behaviours must be explicitly conceived as a process that consists of at least a motivation phase and a volition phase. According to the HAPA, individuals form an intention to engage in a goal-directed behaviour in the motivational phase, whereas more self-regulatory strategies within the volitional phase are needed to ensure an intention is realised. Planning is a key self-regulatory strategy in the volitional phase that has received empirical support in the literature (Gollwitzer, 1993; Hagger, Luszczynska, et al., 2016). Planning is conceptualised as comprising action plans (i.e., plans that specify where, when, and how an intended behaviour is to be performed) and coping plans (i.e., plans that anticipate challenging situations that may obstruct behavioural enactment and mental representation of ways to overcome them; Schwarzer, 2008). Planning has been found to mediate the intention-behaviour relationship (Carraro \& Gaudreau, 2013; Wiedemann, Schüz, Sniehotta, Scholz, \& Schwarzer, 2009), with intervention studies supporting complementary effects of action and coping planning (Kwasnicka, Presseau, White, \& Sniehotta, 2013; Scholz, Sniehotta, Burkert, \& Schwarzer, 2007).

Whereas positive effects of planning on behaviour have been established among young (Fleig et al., 2013a; Hamilton, Bonham, Bishara, Kroon, \& Schwarzer, in press; Reyes Fernández et al., 2015, 2016; Zhou, Gan, Hamilton, \& Schwarzer, in press; Zhou, Gan, Miao, Hamilton, Knoll, \& Schwarzer, 2015; Zhou, Sun, Knoll, Hamilton, \& Schwarzer, 2015) and middle-aged adults (Fleig et al., 2013b; Hamilton, Cox, \& White, 2012; Reuter et 
al., 2010), few studies investigating planning have focused specifically on older adults (e.g., Wolff, Warner, Ziegelmann, Wurm, \& Kliegel, 2016). In the dearth of studies that have targeted older adults, the evidence is equivocal. For example, in one study testing an extended TPB intervention on older adults with multiple morbidities, planning was found to moderate the intention-PA relationship, with participants in the intervention group reporting higher PA levels at 6-months follow-up than the control group (White et al., 2012). In contrast, in a study including retired individuals, Caudroit, Stephan, and Le Scanff (2011) found that planning did not predict PA at 6-months follow-up; instead, participants' PA levels were directly predicted by PA intention at baseline. As older adults are often faced with agerelated illness which can obstruct their PA (Morris, McAuley, \& Motl, 2008), obtaining a clear understanding of the role of self-regulatory strategies such as planning for PA in older adults may be particularly informative for interventions aiming to facilitate PA in this at-risk population group for PA decline (Wolff et al., 2016).

The extant research offers support for the investigation of volitional factors in older adults. It appears that self-regulating mechanisms may be age-specific (Reuter et al., 2010), since older adults have been found to have higher levels of planning than middle-aged adults (Scholz et al., 2007). In addition, the strength of the planning-PA relationship tends to increase with age (Reuter et al., 2010). Considering that planning has been identified as an important construct for facilitating PA in other groups such as adults (Kwasnicka et al., 2013; Reuter et al., 2010) and adult rehabilitation patients (Fleig et al., 2013b; Sniehotta, Scholz, \& Schwarzer, 2005; Ziegelmann, Luszczynska, Lippke, \& Schwarzer, 2007), it can be expected that planning could have a positive impact on the intention-behaviour link also in older adults. While prevailing health-behaviour theories such as the TPB (Ajzen, 1991) and HAPA (Schwarzer, 2008) account for psychological processes that are a result of conscious, reflective efforts, non-conscious (and more reactive) processes might also shape individual 
behavioural decision making (Armitage, 2015; Evans, 2008; Hofmann, Friese, \& Wiers, 2008; Sheeran, Gollwitzer, \& Bargh, 2013).

\section{Non-conscious, Automatic Processes}

In trying to understand the complexities of human behaviour, researchers have recognised that behavioural decision making may be influenced by both conscious, reflective processes and non-conscious, automatic processes (Gardner, 2015; Hagger \& Chatzisarantis, 2014; Hollands, Marteau, \& Fletcher, 2016). Dual-systems theories of behaviour provide an account for the influence of both the reflective and automatic systems operating in parallel to affect behaviour (Evans, 2008; Strack \& Deutsch, 2004). The reflective impulsive model (RIM), devised by Strack and Deutsch (2004), draws together the research on these two independent systems of motivation and how they independently influence behaviour, explaining human behaviour as a joint task of reflective (explicit) and impulsive/automatic (implicit) systems. The model posits that the two systems operate in parallel, maintaining concurrent activity and competing for control of overt responses. More specifically, the reflective system executes behaviour through the use of an explicit decision-making process whereby motivational processes such as intentions are considered. This process involves the use of a high volume of cognitive capacity and, hence, distraction or extreme levels of arousal can interfere with the reflective system or cause it to disengage. On the other hand, the impulsive system operates outside of conscious awareness and requires little cognitive capacity, controlling behaviour in suboptimal conditions.

In a recent study, Presseau et al. (2014) tested a dual-process model applied to clinician behaviour in managing six health-related behaviours. Results supported the applicability of a dual-process model in three behaviours, with reflective processes operating in parallel to automatic processes. Similarly, Keatley et al. (2012), who tested the effects of explicit and 
implicit motivation, found that implicit motives predicted students' PA (but not condom use or healthy eating). These findings concur with other studies (Allom et al., 2016; Hagger \& Chatzisarantis, 2014; Mullan et al., 2016) that emphasised the key roles of both conscious, reflective and non-conscious, automatic processes for health-behaviour change.

Automatic processes may be especially important for behaviours that have become a habit through frequent repetition over time. Thus, to measure automatic processes, habit strength has been proposed as a viable construct (Gardner, 2015; Verplanken \& Melkevik, 2008). While there are a variety of definitions pertaining to the concept of habit (see Gardner, 2015), recent conceptualisations of habit define it as "a process by which a stimulus automatically generates an impulse towards action, based on learned stimulus-response associations" (Gardner, 2015, p. 280). Accordingly, by consistent activation of the association between a specific contextual cue that triggers the behaviour, such as a particular time of day (Wood, Tam, \& Witt, 2005), and behavioral response, the impulse to enact the behaviour becomes triggered automatically and without conscious control. For example, experimental evidence suggests that self-monitoring and promotion of consistent and context-dependent practice of exercises can strengthen the automaticity of performing the exercises (Fleig, McAllister, Chen, et al., 2016). This supports a dual-process approach to PA decision making and suggests that while PA may initially be the product of one's intention (e.g., an older person deciding to start to exercise because of health concerns), after repeatedly choosing a behaviour in a stable context (e.g., going for a walk in the morning around the neighbourhood block) the behaviour may become habitual (Fleig, McAllister, Chen, et al., 2016; Fujii \& Gärling, 2003; Lally \& Gardner, 2013). Overall, the renewed interest in the effects of habit on behaviour has shown support for the construct in the prediction of various health-related behaviours (Gardner, 2015), including PA (Allom et al., 2016; Phillips \& Gardner, 2016; Mullan et al., 2016; Rhodes, de Bruijn, \& Matheson, 2010). 
Although the social-cognitive line of health-behaviour research has provided valuable knowledge of the conscious, reflective antecedents of health-related behaviours (Ajzen, 1991; Schwarzer, 2008), integration of other theories that propose alternative processes guiding health behaviour offers a means of advancing theory towards a more comprehensive understanding of behaviour (Hagger, 2009; Sheeran et al., 2013). Dual-process theories (Evans, 2008; Strack \& Deutsch, 2004) appear useful for furthering our knowledge about psychological processes that underpin human behaviour (Presseau et al., 2014). Currently, there is a gap in our understanding of the multiple processes underpinning older adults' PA, and the role of both conscious, reflective and non-conscious, automatic processes (Maher \& Conroy, 2015). An integration of theoretical concepts that has considered the effects of these multiple processes has, to the authors' knowledge, not yet been applied to an understanding of PA in older adults. Such knowledge can inform theory development and also provide an indication of appropriate behaviour change techniques that might best facilitate key influences on PA.

\section{The Current Study}

To investigate conscious, reflective processes and non-conscious, automatic processes, based on extant empirical literature and theoretical evidence (e.g., Hagger \& Chatzisarantis, 2014), we examined the roles of motivational (behavioural intention), volitional (action planning and coping planning), and automatic (habit strength) processes for older adults' PA. Adopting a longitudinal design with three measurement points, the following hypotheses were developed. First, we examined the effects of key self-regulatory strategies (i.e., action planning and coping planning) in the volitional phase of decision making on the intentionbehaviour link. Consistent with the HAPA (Schwarzer, 2008), we hypothesised two single mediation paths from intention through action planning and coping planning to PA (H1). However, in accord with the TPB (Ajzen, 1991), we also expected intention to have a direct 
effect on PA (H2). Second, we examined the role of automatic processes; specifically, the effect of habit strength, as an indicator of automatic processes, on PA. In line with previous research (Presseau et al., 2014) and the RIM (Strack \& Deutsch, 2004) we assumed that nonconscious, automatic processes would operate in parallel to conscious, reflective processes; accordingly, we expected habit would directly predict PA behaviour (H3).

\section{Method}

The current study was part of a larger program of research investigating the processes underpinning older adults' PA intentions and behaviour (see XX [references blinded for review] for another paper arising from this research program). The current paper focuses on understanding the roles of conscious and non-conscious processes on older adults' PA, specifically focusing on the integration of motivational, volitional, and automatic processes. Ethical approval for the study was granted by the University Human Research Ethics Committee.

\section{Participants}

Participants were recruited via advertisements in local newsletters, face-to-face presentations at community events, and word of mouth. Community-dwelling older adults provided consent to participate in the study and were screened for eligibility. Participants were included if they were aged 65 years or older, resided independently in a communitydwelling, and were able to engage in PA of at least moderate intensity; excluded, if they reported any medical advice to refrain from PA due to a medical reason. Participants completed the main assessment (Time 1; $N=215$; two participants were excluded due to not meeting the selection criteria), either paper-based or online, followed by two phone-based assessments, conducted one week (Time $2 ; N=163$ ) and two weeks (Time $3 ; N=165$ ) later. Participants' progress is presented in Figure 1. Participants who completed all questionnaires 
were included in a prize draw to win one of five AUD\$20 vouchers. Participants provided a unique code identifier that allowed matching of assessment points.

The mean age of the longitudinal sample ( $77.5 \%$ of the initial sample) was 73.8 years ( $S D$ $=7.0 ;$ range $=65-95$ years), and included $66.7 \%$ of women. Participants were predominately retired (87.3\%), of non-university education (64.6\%), had gross weekly income under the national average (up to $\$ 1,000=68 \%$ ), and reported experiencing an average of two health conditions $(S D=1.5$, range $=1-7)$. The attrition between Time 1 and Time 2 was $23.5 \%$, and between Time 1 and Time 3, 22.5\%, lower than the rate observed in previous studies (Caudroit et al., 2011). Drop-out analysis indicated that participants who completed Time 1 and Time 2 assessment points were more often females $\left(\chi^{2}=5.17, p=.02\right)$ and had a higher education level $\left(\chi^{2}=5.23, p=.02\right)$ than those who completed only Time 1 . Participants who completed Time 1 and Time 3 assessment points, however, only differed from those who completed only Time 1 in having a higher level of education $\left(\chi^{2}=4.36, p=\right.$ .03). No other significant differences were identified between the comparison samples for PA intention, action planning and coping planning, habit strength, and sociodemographic variables (age, sex, marital status, income, and, multimorbidity; all $p>.05$ ).

\section{Measures}

Measures included participants' demographic characteristics, PA intentions, and habit strength (Time 1); followed by action planning and coping planning (Time 2); and the target behaviour, regular PA (Time 3). The target behaviour was defined at the start of each survey as "behaviour that is of at least moderate intensity and performed for at least 30 minutes on 5 days or more of the week", following the Physical Activity Recommendations for Older Adults (Department of Health, 2014). Unless otherwise stated, responses were rated on a 7point scale ranging from strongly disagree (1) to strongly agree (7). 
Intention. Three items at Time 1 assessed the strength of intention to perform regular PA (Ajzen, 1991): "It is likely that I will be regularly physically active"; "I intend to be regularly physically active"; and, "I expect that I will be regularly physically active".

Habit strength. The strength of PA habit was assessed at Time 1 using the 4-item SelfReport Behavioural Automaticity Index (Gardner, Abraham, Lally, \& de Bruijn, 2012), all positively scored: "Regular physical activity is something ... ", "I do automatically"; "I do without having to consciously remember"; "I do without thinking"; and, "I start doing before I realise I'm doing it".

Planning. Planning was measured at Time 2 by two 4 -item scales that assessed participants' plans about engaging in the target behaviour (Sniehotta et al., 2005): action planning scale (e.g., "I have made a detailed plan regarding when to do regular PA"); and coping planning scale (e.g., "I have made a detailed plan regarding what to do if something interferes with my plans"). All items were scored from strongly disagree (1) to strongly agree (4).

Covariates. Participants' demographic characteristics, selected based on their association with older adults' PA in previous research (van Stralen, De Vries, Mudde, Bolman, \& Lechner, 2009), were entered into the analysis as control variables. These variables included sex (male, female), age (in years), socio-economic status, and multimorbidity. For socioeconomic status, participants were asked to indicate their average gross household income per week. Responses were dichotomised into below average ( $\leq 1,000$ AUD) and above average (> 1,000 AUD), with respect to the Australian average income (ABS, 2012). In addition, participants reported the presence of 14 health conditions, following Menec (2003). The sum of positive responses was computed to obtain a measure of morbidity. 
Behaviour. Self-reported PA behaviour at Time 3 was assessed using three 7-point singlescales (Ajzen, 1991): “On how many days in the past week (past 7 days) have you engaged in at least 30 minutes of at least moderate-intensity PA?"; "In the previous week, how often did you engage in regular physical activity?"; and, "In the previous week, to what extent did you engage in regular physical activity?". Similar items have been found to be valid in assessing PA against longer self-report and objective measures of PA (Hamilton, White, \& Cuddihy, 2012). For example, the first single-item, which was chosen specifically because it corresponds to the current PA guidelines (Department of Health, 2014), showed a moderate correlation $(r=.51, p<.001)$ between the single-item and 7-day PA recall and a very strong correlation $(r=.81, p<.001)$ between the single-item and pedometer steps (Hamilton et al., 2012).

\section{Data Analysis}

In the current study, structural equation modelling with Mplus 7 was used to test the structural assumptions within the proposed model (see Figure 2). The hypothetical model consisted of five latent variables including intention, habit strength, action planning, coping planning, and PA. All latent variables were specified with the manifest indicators described in the Measures section. Sex, age, socio-economic status, and multimorbidity were included as covariates. We assessed the model fit based on the comparative fit index (CFI), the rootmean-square error of approximation (RMSEA), and the Tucker-Lewis-Index (TLI). Missing data $(<5 \%)$ were treated using the full maximum likelihood (FIML) algorithm (Enders \& Bandalos, 2001). Specific indirect effects of intention on PA were estimated using biascorrected bootstrapping with 5000 resamples.

\section{Results}


Table 1 presents the estimated means, standard deviations, and factor loadings for each construct. Participants reported moderate levels of PA intentions, habit strength, and PA behaviour, and slightly lower, albeit still moderate levels of action planning and coping planning. Intentions (Time 1), habit strength (Time 1), action planning (Time 2), and coping planning (Time 2) were all significantly associated with PA behaviour at Time 3, with intentions being the strongest predictor of PA. The hypothesized model showed a good fit to the data $\left(\mathrm{RMSEA}=.05, \mathrm{CFI}=.97, \mathrm{TLI}=.96, \chi^{2}(179)=249.47, \chi^{2} / \mathrm{df}=1.39\right)$. Figure 2 presents the standardised parameter estimates for the tested model. Among all independent variables, intentions, habit strength, and action planning, but not coping planning, predicted PA at Time 3 follow-up. The specific indirect effect of intentions through action planning on PA was $\beta=.17\left(\mathrm{CI}_{\mathrm{BCA}}=.01\right.$ to .31$)$, while the specific indirect effect of intentions through coping planning on $\mathrm{PA}$ was $\beta=-.02\left(\mathrm{CI} \mathrm{ICA}_{\mathrm{B}}=-.18\right.$ to .11$)$. The hypothesised model accounted for $44 \%$ of the variance in PA behaviour at Time 3. Regarding the covariates, age, income, and multimorbidity were not associated with PA (all $p>.05$ ); however, sex was negatively associated with action planning and coping planning yet positively associated with PA behaviour $(p<.05$, see Figure 2), meaning that men used action planning and coping planning less often than women but engaged in more PA than women.

\section{Discussion}

The aim of the current study was to test an integrated dual-process model of older adults' PA which, to the authors' knowledge, is the first to apply such an approach within the context of PA in the older adult population. Overall, the findings provided support for the dualprocess model of PA in older adults; conscious, reflective processes (i.e., performing PA in an intentional manner) appeared to be crucial for PA behaviour, displaying both direct and indirect effects on PA, while operating in parallel to non-conscious, automatic processes (i.e., performing PA in a reactive manner). This advance in theoretical knowledge is important and 
suggests that to improve PA of older adults, intervention designers and practitioners need to choose behaviour change techniques (Michie et al., 2013) that tap into both processes, and thereby ensure the complementary nature of conscious and non-conscious psychological processes.

Partly supporting hypothesis 1 , findings of the current study showed that action planning mediated the relationship between intentions and behaviour, adding to the scientific research on the role of planning for PA in older adults. Specifically, these findings suggest that when older adults are motivated to engage in regular PA, the use of cognitive self-regulating strategies such as making specific plans about where, when, and how to engage in PA, may help facilitate acting on intentions. This finding contradicts previous research on retired individuals which found no mediating role of planning on the intention-PA relationship (Caudroit et al., 2011). This may be due to the difference in the samples; participants in the latter study were members of a voluntary university-based organisation, whereas participants in the current study were predominately of non-university education and on average older (65.4 vs. 73.8 years, respectively). Thus, the former sample of older adults may have been healthier and more used to balancing different commitments and enacting their intentions with less planning. However, our findings on the mediating role of planning are in line with the theoretical propositions of the HAPA (Schwarzer, 2008) and previous empirical evidence (Fleig et al., 2013a,b; Hamilton, Cox, et al., 2012; Sniehotta, Schwarzer, Scholz, \& Schüz, 2005). In addition, and consistent with this research, our findings provide support for differentiating between both types of planning. In the current study, action planning, but not coping planning, predicted behaviour. This implies that older adults are likely to benefit from linking specific characteristics of regular PA (e.g., where, when, and how to perform it) when wanting to initiate and maintain PA, while their PA engagement is not necessarily predictive 
of whether one anticipates barriers to plans to be active and makes plans to overcome such barriers.

The finding that coping planning did not mediate the intention-behaviour link is noteworthy, particularly as previous research found that older adults have higher levels of coping planning than younger adults (Scholz et al., 2007). One potential avenue of reasoning underlying the weak intention-coping planning-PA link may be in older adults' time perspective. While previous research suggests that older adults have a shorter global future time perspective (Tasdemir-Ozdes, Strickland-Hughes, Bluck, \& Ebner, 2016), and that for those with limited time perspective planning has a greater effect on PA (Gellert, Ziegelmann, Lippke, \& Schwarzer, 2012), it is noteworthy that in our earlier study (XX [citation blinded for review]) some older adults held a strong future-time perspective towards health. Given that the sample of participants in the current study was rather active (for example, they received no medical advice to refrain from PA), it seems reasonable to speculate that older adults' time perspective may have been predominately future oriented, and thus, making the effects of planning on behaviour smaller. In the absence of information about the time perspective among older adults in the current study, this line of potential explanation is not possible to test. Future studies may therefore want to explore relationships among these concepts; in particular, the role of future time perspective on the intention-planning-PA relationship. Alternatively, it is possible that the timeframe of the study was too short for participants to encounter any barriers obstructing their PA engagement. For instance, coping planning may exhibit a delayed effect on PA, and thus, be more crucial in the long term maintenance of behaviour (Ziegelmann, Lipke, \& Schwarzer, 2006).

Overall, our findings indicate that planning strategies to cope with anticipated barriers and challenges may be less important for older adults than mentally linking specific situational cues to the actual behaviour via action planning strategies, suggesting that developing simple 
action plans may be sufficient for older adults to action their intentions in the short term. No conclusions about this relationship, however, can be made for the long term. The findings also highlight the importance of both motivational and volitional processes for understanding older adults' PA. However, it should be noted, consistent with Ajzen (1991), that the findings supported a direct path from intention to behaviour, highlighting the importance of motivational processes for older adults' PA. This finding is also consistent with Caudroit et al. (2011) who found that intentions directly predicted PA, without the mediating role of planning.

It should also be noted that, given the effect of sex in the current study, the role of this demographic variable on self-regulatory strategies such as action and coping planning should be considered when examining older adults' health behaviour. Specifically, the findings showed that older women were more likely to make action plans, and to a smaller extent also coping plans, than older men, yet older men were more physically active. These findings are consistent with other studies that have shown sex differences in regards to planning (Hankonen, Absetz, Ghisletta, Renner, \& Uutela, 2010; Hamilton, Cox, et al., 2012). Given that older women are typically reported to have lower levels of moderate and strenuous PA than men (Lim \& Taylor, 2005), it may be beneficial to provide older women with planning interventions that would strengthen the link between intentions and behaviour by specifying greater detail of when, where, and how to engage in PA (Scholz et al., 2007). Such interventions, however, may need to offer assisted-planning (rather than passive selfadministered planning) to be beneficial for older adults (Ziegelmann et al., 2006).

Consistent with previous research (Gardner, de Bruijn, \& Lally, 2011), our results also showed that PA behaviour was predicted by habit strength, with the effect being observed over and above that of intention. This highlights the role of automatic processes in addition to reflective processes for older adults' PA. According to the habit theory (Gardner, 2015), 
habit-generated impulses may be either enacted, or inhibited, if the cue-response association is interrupted by other (contradicting) factors, including conscious decision-making processes. Furthermore, in the context of dual-process models (Evans, 2008), habitual (automatic) processes may work either in parallel with reflective processes or act in competition with them. Consistent with previous research (Presseau et al., 2014) and the RIM (Strack \& Deutsch, 2004), the current results support the parallel (dual) processing approach, which is demonstrated by PA being predicted by both conscious, reflective (involving motivational and volitional factors) and non-conscious, automatic processes (including habitual behaviour).

The finding that both conscious and non-conscious processes are involved in older adults' PA engagement is important for several reasons. First, it provides justification for integrating multiple processes from different theories, including TPB where intention is central to the model (Ajzen, 1991), HAPA where volitional processes are important for translating intentions into behaviour (Schwarzer, 2008), and habit theory where automatic processes are considered important for behavioural decision making (Gardner, 2015; Strack \& Deutsch, 2004). Second, it indicates that PA interventions, to be efficacious, should target both reflective and automatic processes to increase PA in older adults. In support of this, recent research showed that a PA-promoting message (Cheval, Sarrazin, Isoard-Gautheur, Radel, \& Friese, 2015) predicted post-message PA intentions, and that both intentions and impulsive tendencies towards PA predicted subsequent PA behaviour among adults. Furthermore, by demonstrating that conscious, reflective decision making operates in parallel to more nonconscious, habitual processes, future interventions might benefit by using reflective decision making to facilitate development of habitual behaviour regulation (e.g., Fleig, McAllister, Chen, et al., 2016), thereby attempting to make regular PA less effortful. Indeed, previous research and theory (Gardner, 2015) suggests that exercise habit strength can be increased 
directly by facilitating formation of exercise intention, as well as via an indirect pathway of intentions via action planning on behaviour (Fleig et al., 2013b).

\section{Study Limitations}

The current study has several limitations. The use of self-report measurement of PA may be less accurate than an objective assessment of PA levels. However, previous research has demonstrated that self-report measures are reliable and valid in assessing PA levels (Hamilton et al., 2012; Milton, Bull, \& Bauman, 2011). Nevertheless, given that previous research has shown that older adults tend to overestimate their PA levels (Visser, Brychta, Chen, \& Koster, 2014), it may be important for future studies to test the applicability of the model using an objective PA measure such as accelerometers. In addition, the longitudinal correlational design, albeit testing two temporal mediator paths, means that assumptions about the causal nature among predictors and PA cannot be determined. An experimental design, where the potential predictors would be manipulated in a controlled environment, would be needed in order to test whether the changes in specific variables do indeed produce changes in behaviour.

Furthermore, the lack of multiple follow-up points beyond a two-week period precludes differentiating between factors that are related to initiation and those that may be essential for maintenance of PA. The three waves of data collection were spaced one week apart to avoid common method variance contaminating the data, with measures at each time point based on an empirically-supported theoretical temporal sequence based on the HAPA (Schwarzer, 2008). Nevertheless, some determinants of PA in older adults may be more important for adopting a new PA behaviour than for maintaining an existing routine. As such, the finding that coping planning did not mediate the intention-behaviour relationship should be interpreted in light of the fact that no change has been examined and the nature of coping 
planning which becomes more influential after a slightly longer time of engaging in a PA routine (Ziegelmann et al., 2006).

Finally, it should be noted that the lack of control for baseline behaviour may present as a further limitation of our findings. Although we acknowledge the argument that all variables known to predict behaviour, as is often the case with past behaviour, should be included for the purpose of correct model specification (Armitage \& Conner, 2001) we also acknowledge the argument that past behaviour is not amendable to change (Ajzen, 2002), and if included in the model, may attenuate the effects of social cognitive variables that can be manipulated in behaviour change interventions. Thus, we considered it more relevant to investigate the degree to which PA has become automatised (by measuring habit strength), rather than proposing a model that focuses on the role of past behaviour. Nevertheless, this warrants some caution in interpreting the current findings which provide evidence that both conscious and non-conscious processes impact older adults' PA.

\section{Study Implications and Future Directions}

In terms of scientific and theoretical importance, the current study is significant in its use of an integrative theoretical approach to develop a model using a dual-process approach that explains older adults' decisions for regular engagement in PA. By including three measurement points, this study was able to empirically test two theoretically proposed mediator paths, providing evidence for a model that can be tested further using experimental designs to ultimately change PA behaviour. As such, these findings can inform the development of integrative theories of behaviour change which have been strongly advocated recently as the way of moving the science forward to help better understand and predict human behaviour (Conner, 2015; Hagger \& Chatzisarantis, 2014; Hamilton, Cox, et al., 2012). 
In terms of impact, the current study is significant as it targets a key health behaviour in an at-risk group which has implications both at a national level and within the international context. To facilitate PA in older adults, motivational-type interventions are suggested to target intention formation regarding regular PA; for example, techniques such as goal setting or creating a behavioural contract may assist in strengthening one's conscious commitment to engage in recommended amounts and levels of PA. The findings also suggest that older adults would benefit from encouragement of "context-dependent repetition" (Lally \& Gardner, 2013, p. 137), to promote habit formation which could be facilitated by making detailed plans about the context in which to engage in PA (e.g., every morning, before breakfast, I will go for a 30- minute walk in a nearby park; Fleig et al., 2016b). While research also suggests that planning interventions can, indeed, be efficacious in increasing PA levels, especially when individuals are supported during the process of forming plans (Kwasnicka et al., 2013), it is recommended that future studies explore more concretely how planning interventions targeting older adults specifically would be best implemented to effectively increase their PA levels.

Furthermore, to broaden the understanding of multiple psychological processes guiding older adults' PA behaviour, it seems important that "when we identify processes as conscious or non-conscious, we must be clear about the scale and level of analysis we are employing" (Hollands et al., 2016, p. 3). While in the current study we conceptualise planning as a conscious process thus assuming that goal activation results from a conscious choice, we acknowledge that goals can be activated also non-consciously (Armitage, 2015; Bargh, Gollwitzer, Lee-Chai, Barndollar, \& Trötschel, 2001). In moving forward, future research should continue using process models to better understand health-related behaviour.

Current interventions designed to facilitate PA tend to focus on conscious decision-making processes and, indeed, have found the use of self-regulatory techniques effective in 
promoting behaviour change (Michie et al., 2013). However, a meta-analysis of interventions aiming to increase PA among older adults showed that a combination of cognitive-type components, which aim to change cognitive processes such as attitudes and beliefs, and behavioural-type intervention components, which focus on changing the actual behaviour, is more effective than interventions using either component-type alone (Chase, 2015). Given that current interventions more commonly employ cognitive than behavioural-type intervention components (Chase, 2015), the current findings suggest that future interventions should complement cognitive-type techniques (targeting intention formation and action planning) with behavioural-type techniques which would also activate automatic cognitive processes, thereby increasing the strength of PA habit. By identifying key theory-based constructs, the findings of the current study can be translated into practice by linking key predictors identified with relevant behaviour change techniques (Michie, van Stralen, \& West, 2011), to develop effective empirical- and theory-based interventions to facilitate PA in older adults.

\section{References}

ABS. (2012). Australian Demographic Statistics (Catalogue No. 3101.0). Canberra: ABS.

Retrieved from http://www.abs.gov.au/ausstats/abs@.nsf/mf/3101.0

Ajzen, I. (2002). Residual effects of past on later behavior: habituation and reasoned action perspectives. Personality and Social Psychology Review, 6, 107-122. doi: 10.1207/S15327957PSPR0602_02

Ajzen, I. (1991). The theory of planned behavior. Organizational Behavior and Human Decision Processes, 50, 179-211. doi: 10.1016/0749-5978(91)90020-T

Allom, V., Mullan, B., Cowie, E., \& Hamilton, K. (2016). Physical activity and transitioning to college: The importance of intentions and habits. American Journal of Health Behavior, 40(2), 280-290. doi: http://dx.doi.org.libraryproxy.griffith.edu.au/10.5993/AJHB.40.2.13 
Armitage, C. J. (2015). Time to retire the theory of planned behaviour? A commentary on Sniehotta, Presseau and Araújo-Soares. Health Psychology Review, 9(2), 151-155. doi: $10.1080 / 17437199.2014 .892148$

Armitage, C. J., \& Conner, M. (2001). Efficacy of the theory of planned behaviour: a metaanalytic review. British Journal of Social Psychology, 40, 471-499. doi: $10.1348 / 014466601164939$

Bargh, J. A., Gollwitzer, P. M., Lee-Chai, A., Barndollar, K., \& Trötschel, R. (2001). The automated will: Nonconscious activation and pursuit of behavioral goals. Journal of Personality and Social Psychology, 81(6), 1014-1027. doi: 10.1037/0022-3514.81.6.1014

Caudroit, J., Stephan, Y., \& Le Scanff, C. (2011). Social cognitive determinants of physical activity among retired older individuals: An application of the health action process approach. British Journal of Health Psychology, 16(2), 404-417. doi: $10.1348 / 135910710 X 518324$

Carraro, N., \& Gaudreau, P. (2013). Spontaneous and experimentally induced action planning and coping planning for physical activity: A meta-analysis. Psychology of Sport and Exercise, 14(2), 228-248. doi: 10.1016/j.psychsport.2012.10.004

Chase, J. A. (2015). Interventions to increase physical activity among older adults: A metaanalysis. The Gerontologist, 55(4), 706-718. doi: 10.1207/S15324796ABM2403_04

Cheval, B., Sarrazin, P., Isoard-Gautheur, S., Radel, R., \& Friese, M. (2015). Reflective and impulsive processes explain (in) effectiveness of messages promoting physical activity: A randomized controlled trial. Health Psychology, 34(1), 10-19. doi: 10.1037/hea0000102

Conner, M. (2015). Extending not retiring the theory of planned behaviour: A commentary on Sniehotta, Presseau and Araújo-Soares. Health Psychology Review, 9(2), 141-145. doi: $10.1080 / 17437199.2014 .899060$ 
Department of Health. (2014). Recommendations on physical activity for health for older Australians. Retrieved from http://www.health.gov.au/internet/main/publishing.nsf/Content/phd-physical-rec-olderguidelines

Enders, C. K., \& Bandalos, D. L. (2001). The relative performance of full information maximum likelihood estimation for missing data in structural equation models. Structural Equation Modeling, 8(3), 430-457.doi: 10.1207/S15328007SEM0803_5

Evans, J. S. B. (2008). Dual-processing accounts of reasoning, judgment, and social cognition. Annual Review of Psychology, 59, 255-278. doi:

10.1146/annurev.psych.59.103006.093629

Fleig, L., Pomp, S., Parschau, L., Barz, M., Lange, D., Schwarzer, R., \& Lippke, S. (2013a). From intentions via planning and behavior to physical exercise habits. Psychology of Sport and Exercise, 14(5), 632-639. doi: 10.1016/j.psychsport.2013.03.006

Fleig, L., Pomp, S., Schwarzer, R., \& Lippke, S. (2013b). Promoting exercise maintenance: How interventions with booster sessions improve long-term rehabilitation outcomes. Rehabilitation Psychology, 58(4), 323. doi: 10.1037/a0033885

Fleig, L., McAllister, M. M., Brasher, P., Cook, W. L., Guy, P., Puyat, J. H., . . Ashe, M. C. (2016). Sedentary behavior and physical activity patterns in older adults after hip fracture: A call to action. Journal of Aging and Physical Activity, 24(1), 79-8. doi: 10.1123/japa.2015-0013

Fleig, L., McAllister, M. M., Chen, P., Iverson, J., Milne, K., McKay, H. A., . . Ashe, M. C. (2016). Health behaviour change theory meets falls prevention: Feasibility of a habit-based balance and strength exercise intervention for older adults. Psychology of Sport and Exercise, 22, 114-122. doi: 10.1016/j.psychsport.2015.07.002 
Fujii, S., \& Gärling, T. (2003). Application of attitude theory for improved predictive accuracy of stated preference methods in travel demand analysis. Transportation Research Part A: Policy and Practice, 37(4), 389-402. doi: 10.1016/S0965-8564(02)00032-0

Gardner, B. (2015). A review and analysis of the use of 'habit'in understanding, predicting and influencing health-related behaviour. Health Psychology Review, 9(3), 277-295. doi: $10.1080 / 17437199.2013 .876238$

Gardner, B., Abraham, C., Lally, P., \& de Bruijn, G.-J. (2012). Towards parsimony in habit measurement: Testing the convergent and predictive validity of an automaticity subscale of the Self-Report Habit Index. International Journal of Behavioral Nutrition and Physical Activity, 9(1), 102-113. doi: 10.1186/1479-5868-9-102

Gardner, B., de Bruijn, G.-J., \& Lally, P. (2011). A systematic review and meta-analysis of applications of the self-report habit index to nutrition and physical activity behaviours. Annals of Behavioral Medicine, 42(2), 174-187. doi: 10.1007/s12160-011-9282-0

Gellert, P., Ziegelmann, J. P., Lippke, S., \& Schwarzer, R. (2012). Future time perspective and health behaviors: Temporal framing of self-regulatory processes in physical exercise and dietary behaviors. Annals of Behavioral Medicine, 43(2), 208-218. doi:

$10.1007 / \mathrm{s} 12160-011-9312-\mathrm{y}$

Gollwitzer, P. M. (1993). Goal achievement: The role of intentions. European Review of Social Psychology, 4(1), 141-18. doi: 10.1080/14792779343000059

Hankonen, N., Absetz, P., Ghisletta, P., Renner, B., \& Uutela, A. (2010). Gender differences in social cognitive determinants of exercise adoption. Psychology and Health, 25(1), 5569. doi: 10.1080/08870440902736972

Hagger, M. S. (2009). Theoretical integration in health psychology: Unifying ideas and complementary explanations. British Journal of Health Psychology, 14(2), 189-194. doi: $10.1348 / 135910708 \times 397034$ 
Hagger, M. S., \& Chatzisarantis, N. L. D. (2014). An integrated behavior change model for physical activity. Exercise and Sport Sciences Reviews, 42(2), 62-69. doi:

\subsection{9/JES.0000000000000008}

Hagger, M. S., Chatzisarantis, N. L. D., \& Biddle, S. J. H. (2002). A meta-analytic review of the theories of reasoned action and planned behavior in physical activity: Predictive validity and the contribution of additional variables. Journal of Sport and Exercise Psychology, 24(1), 3-32. doi: 10.1123/jsep.24.1.3

Hagger, M. S., Luszczynska, A., de Wit, J., Benyamini, Y., Burkert, S., Chamberland, P.-E., . .. French, D. P. (2016). Implementation intention and planning interventions in health psychology: Recommendations from the Synergy expert group for research and practice. Psychology \& Health, 1-26. doi: 10.1111/aphw.12017

Hamilton, K., Cox, S., \& White, K. M. (2012). Testing a model of physical activity among mothers and fathers of young children: Integrating self-determined motivation, planning, and the theory of planned behavior. Journal of Sport \& Exercise Psychology, 34, 124-145. doi: $10.1123 /$ jsep.34.1.124

Hamilton, K., White, K. M., \& Cuddihy, T. (2012). Using a single-item physical activity measure to describe and validate parents' physical activity patterns. Research Quarterly for Exercise and Sport, 83(2), 340-345. Retrieved from http://www.tandfonline.com/doi/abs/10.1080/02701367.2012.10599865

Hamilton, K., Bonham, M., Bishara, J., Kroon, J., \& Schwarzer, R. (in press). Translating dental flossing intentions into behavior: A longitudinal investigation of the mediating effect of planning and self-efficacy. International Journal of Behavioral Medicine.

Hofmann, W., Friese, M., \& Wiers, R. W. (2008). Impulsive versus reflective influences on health behavior: A theoretical framework and empirical review. Health Psychology Review, 2(2), 111-137. doi: 10.1080/17437190802617668 
Hollands, G. J., Marteau, T. M., \& Fletcher, P. C. (2016). Non-conscious processes in changing health-related behaviour: a conceptual analysis and framework. Health Psychology Review, 1-14. doi: 10.1080/17437199.2015.1138093

Keatley, D., Clarke, D. D., \& Hagger, M. S. (2012). Investigating the predictive validity of implicit and explicit measures of motivation on condom use, physical activity and healthy eating. Psychology \& Health, 27(5), 550-569. doi: 10.1080/08870446.2011.605451

Kwasnicka, D., Presseau, J., White, M., \& Sniehotta, F. F. (2013). Does planning how to cope with anticipated barriers facilitate health-related behaviour change? A systematic review. Health Psychology Review, 7(2), 129-145. doi: 10.1080/17437199.2013.766832

Lally, P., \& Gardner, B. (2013). Promoting habit formation. Health Psychology Review, 7(1), 137-158. doi: 10.1080/17437199.2011.603640

Lim, K., \& Taylor, L. (2005). Factors associated with physical activity among older peoplea population-based study. Preventive Medicine, 40(1), 33-40. doi: 10.1016/j.ypmed.2004.04.046

Maher, J. P., \& Conroy, D. E. (2015). A dual-process model of older adults' sedentary behavior. Health Psychology, 35(3), 262-272. doi: 10.1037/hea0000300

McEachan, R. R. C., Conner, M., Taylor, N. J., \& Lawton, R. J. (2011). Prospective prediction of health-related behaviours with the theory of planned behaviour: A metaanalysis. Health Psychology Review, 5(2), 97-144. doi: 10.1080/17437199.2010.521684

Menec, V. H. (2003). The relation between everyday activities and successful aging: A 6year longitudinal study. The Journals of Gerontology Series B: Psychological Sciences and Social Sciences, 58(2), 74-S82. doi: 10.1093/geronb/58.2.S74

Michie, S., van Stralen, M. M., \& West, R. (2011). The behaviour change wheel: A new method for characterising and designing behaviour change interventions. Implementation Science, 6(1), 42-47. doi: 10.1186/1748-5908-6-42 
Michie, S., Richardson, M., Johnston, M., Abraham, C., Francis, J., Hardeman, W., . . Wood, C. E. (2013). The behavior change technique taxonomy (v1) of 93 hierarchically clustered techniques: building an international consensus for the reporting of behavior change interventions. Annals of Behavioral Medicine, 46(1), 81-95. doi: 10.1007/s12160013-9486-6

Milton, K., Bull, F., \& Bauman, A. (2011). Reliability and validity testing of a single-item physical activity measure. British Journal of Sports Medicine, 45(3), 203-208. doi: 10.1136/bjsm.2009.068395

Morris, K. S., McAuley, E., \& Motl, R. W. (2008). Neighborhood satisfaction, functional limitations, and self-efficacy influences on physical activity in older women. International Journal of Behavioral Nutrition and Physical Activity, 5(1), 13-20. doi: 10.1186/1479$5868-5-13$

Mullan, B., Henderson, J., Kothe, E., Allom, V., Orbell, S., \& Hamilton, K. (2016). The role of habit and perceived control on health behaviour among pregnant women. American Journal of Health Behavior, 40(3), 291-301. doi: 10.5993/AJHB.40.3.1

Orbell, S., \& Sheeran, P. (1998). 'Inclined abstainers': A problem for predicting healthrelated behaviour. British Journal of Social Psychology, 37(2), 151-165. doi:10.1111/j.2044-8309.1998.tb01162.x

Phillips, L. A., \& Gardner, B. (2016). Habitual exercise instigation (vs. execution) predicts healthy adults' exercise frequency. Health Psychology, 35(1), 69-77. doi: 10.1037/hea0000249

Presseau, J., Johnston, M., Heponiemi, T., Elovainio, M., Francis, J. J., Eccles, M. P., . . Grimshaw, J. M. (2014). Reflective and automatic processes in health care professional behaviour: a dual process model tested across multiple behaviours. Annals of Behavioral Medicine, 48(3), 347-358. doi: 10.1007/s12160-014-9609-8 
Reuter, T., Ziegelmann, J. P., Wiedemann, A. U., Lippke, S., Schüz, B., \& Aiken, L. S. (2010). Planning bridges the intention-behaviour gap: Age makes a difference and strategy use explains why. Psychology and Health, 25(7), 873-887. doi: $10.1080 / 08870440902939857$

Reyes Fernández, B., Fleig, L., Godinho, C. A., Montenegro Montenegro, E., Knoll, N., \& Schwarzer, R. (2015). Action control bridges the planning-behaviour gap: A longitudinal study on physical exercise in young adults. Psychology \& Health, 30(8), 911-923. doi: $10.1080 / 08870446.2015 .1006222$

Reyes Fernández, B., Knoll, N., Hamilton, K., Schwarzer, R. (2016). Social-cognitive antecedents of hand washing: Action control bridges the planning-behavior gap. Psychology \& Health, 31(8), 993-1004. doi: 10.1080/08870446.2016.1174236

Rezende, L. F., Rey-López, J. P., Matsudo, V. K., \& do Luiz, O. (2014). Sedentary behavior and health outcomes among older adults: A systematic review. BMC Public Health, 14(1), 333-340. doi: 10.1186/1471-2458-14-333

Rhodes, R. E., de Bruijn, G.-J., \& Matheson, D. (2010). Habit in the physical activity domain: Integration with intention stability and action control. Journal of Sport \& Exercise Psychology, 32(1), 84-98. doi: 10.1123/jsep.32.1.84

Rhodes, R. E., \& de Bruijn, G. J. (2013). How big is the physical activity intention-behaviour gap? A meta-analysis using the action control framework. British Journal of Health Psychology, 18(2), 296-309. doi: 10.1111/bjhp.12032

Scholz, U., Schüz, B., Ziegelmann, J. P., Lippke, S., \& Schwarzer, R. (2008). Beyond behavioural intentions: Planning mediates between intentions and physical activity. British Journal of Health Psychology, 13(3), 479-494. doi: 10.1348/135910707X216062 
Schwarzer, R. (2008). Modeling health behavior change: How to predict and modify the adoption and maintenance of health behaviors. Applied Psychology, 57(1), 1-29. doi: 10.1111/j.1464-0597.2007.00325.x

Schwarzer, R., \& Luszczynska, A. (2008). How to overcome health-compromising behaviors: The health action process approach. European Psychologist, 13(2), 141-151. doi: $10.1027 / 1016-9040.13 .2 .141$

Sheeran, P. (2002). Intention-behavior relations: A conceptual and empirical review. European Review of Social Psychology, 12(1), 1-36. doi: 10.1080/14792772143000003 Sheeran, P., \& Webb, T. L. (2016). The intention-behavior gap. Social and Personality Psychology Compass, 10(9), 503-518. doi: 10.1111/spc3.12265

Sheeran, P., Gollwitzer, P. M., \& Bargh, J. A. (2013). Nonconscious processes and health. Health Psychology, 32(5), 460-473. doi: 10.1037/a0029203

Smith, L., Gardner, B., Fisher, A., \& Hamer, M. (2015). Patterns and correlates of physical activity behaviour over 10 years in older adults: prospective analyses from the English Longitudinal Study of Ageing. BMJ Open, 5(4), 7423-7437. doi: 10.1136/bmjopen-2014007423

Sniehotta, F. F., Scholz, U., \& Schwarzer, R. (2005). Bridging the intention-behaviour gap: Planning, self-efficacy, and action control in the adoption and maintenance of physical exercise. Psychology \& Health, 20(2), 143-160. doi: 10.1080/08870440512331317670

Sniehotta, F. F., Schwarzer, R., Scholz, U., \& Schüz, B. (2005). Action planning and coping planning for long-term lifestyle change: Theory and assessment. European Journal of Social Psychology, 35(4), 565-576. doi: 10.1002/ejsp.258

Strack, F., \& Deutsch, R. (2004). Reflective and impulsive determinants of social behavior. Personality and Social Psychology Review, 8(3), 220-247. doi: 10.1207/s15327957pspr0803_1 
Tasdemir-Ozdes, A., Strickland-Hughes, C. M., Bluck, S., \& Ebner, N. C. (2016). Future perspective and healthy lifestyle choices in adulthood. Psychology and aging, 31(6), 618630. doi: 10.1037/pag0000089

van Stralen, M. M., De Vries, H., Mudde, A. N., Bolman, C., \& Lechner, L. (2009).

Determinants of initiation and maintenance of physical activity among older adults: A literature review. Health Psychology Review, 3(2), 147-207. doi: $10.1080 / 17437190903229462$

Verplanken, B., \& Melkevik, O. (2008). Predicting habit: The case of physical exercise. Psychology of Sport and Exercise, 9(1), 15-26. doi: 10.1016/j.psychsport.2007.01.002

Visser, M., Brychta, R. J., Chen, K. Y., \& Koster, A. (2014). Self-reported adherence to the physical activity recommendation and determinants of misperception in older adults. Journal of Aging and Physical Activity, 22(2), 226-234. doi: 10.1123/japa.2012-0219

White, K. M., Terry, D. J., Troup, C., Rempel, L. A., Norman, P., Mummery, K., . . Kenardy, J. (2012). An extended theory of planned behavior intervention for older adults with type 2 diabetes and cardiovascular disease. Journal of Aging and Physical Activity, 20(3), 281-299. doi: 10.1123/japa.20.3.281

Wiedemann, A. U., Schüz, B., Sniehotta, F., Scholz, U., \& Schwarzer, R. (2009).

Disentangling the relation between intentions, planning, and behaviour: A moderated mediation analysis. Psychology and Health, 24(1), 67-79. doi:

$10.1080 / 08870440801958214$

Wolff, J. K., Warner, L. M., Ziegelmann, J. P., Wurm, S., \& Kliegel, M. (2016). Translating good intentions into physical activity: Older adults with low prospective memory ability profit from planning. Journal of Behavioral Medicine, 39(3), 1-11. doi: 10.1007/s10865015-9707-5 
Wood, W., Tam, L., \& Witt, M. G. (2005). Changing circumstances, disrupting habits. Journal of Personality and Social Psychology, 88(6), 918-933. doi: 10.1037/00223514.88.6.918

Zhou, G., Gan, Y., Hamilton, K., Schwarzer, R. (in press). The role of social support and selfefficacy for planning fruit and vegetable intake. Journal of Nutrition Education \& Behavior.

Zhou, G., Gan, Y., Miao, M., Hamilton, K., Knoll, N., \& Schwarzer, R. (2015). The role of action control and action planning on fruit and vegetable consumption. Appetite, 91, 6468. doi: 10.1016/j.appet.2015.03.022

Zhou, G., Sun, C., Knoll, N., Hamilton, K., \& Schwarzer, R. (2015). Self-efficacy, planning, and action control in an oral self-care intervention. Health Education Research, 30(4), 671-681. doi:10.1093/her/cyv032. doi: 10.1093/her/cyv032

Ziegelmann, J. P., \& Knoll, N. (2015). Future directions in the study of health behavior among older adults. Gerontology, 61(5), 469-476. doi: 10.1159/000369857

Ziegelmann, J. P., Lippke, S., \& Schwarzer, R. (2006). Adoption and maintenance of physical activity: Planning interventions in young, middle-aged, and older adults. Psychology \& Health, 21(2), 145-163. doi: 10.1080/1476832050018891

Ziegelmann, J. P., Luszczynska, A., Lippke, S., \& Schwarzer, R. (2007). Are goal intentions or implementation intentions better predictors of health behavior? A longitudinal study in orthopedic rehabilitation. Rehabilitation Psychology, 52(1), 97-102. doi: 10.10337/00905550.52 .1 .65 


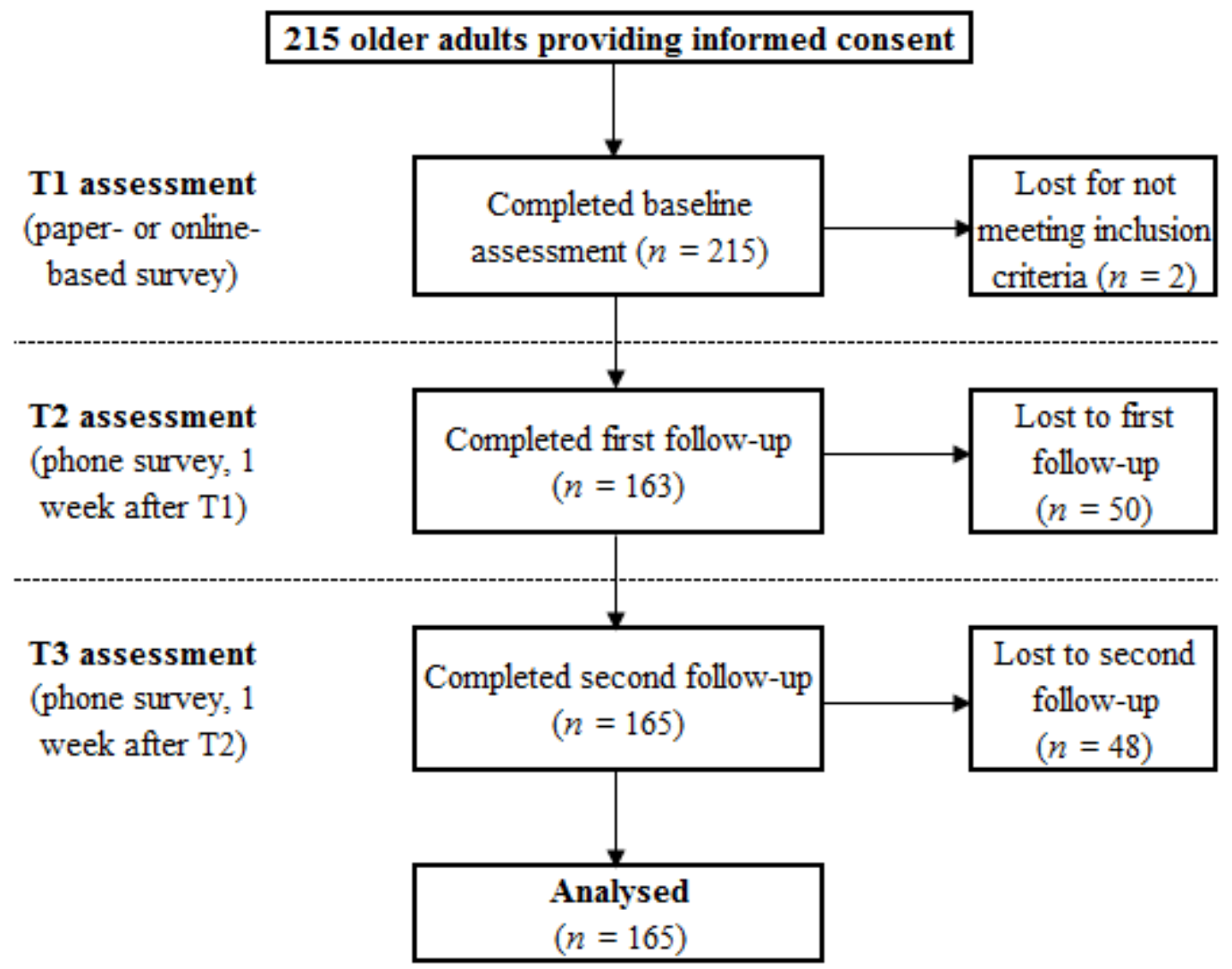

Figure 1. Older adults and physical activity: participant flowchart 


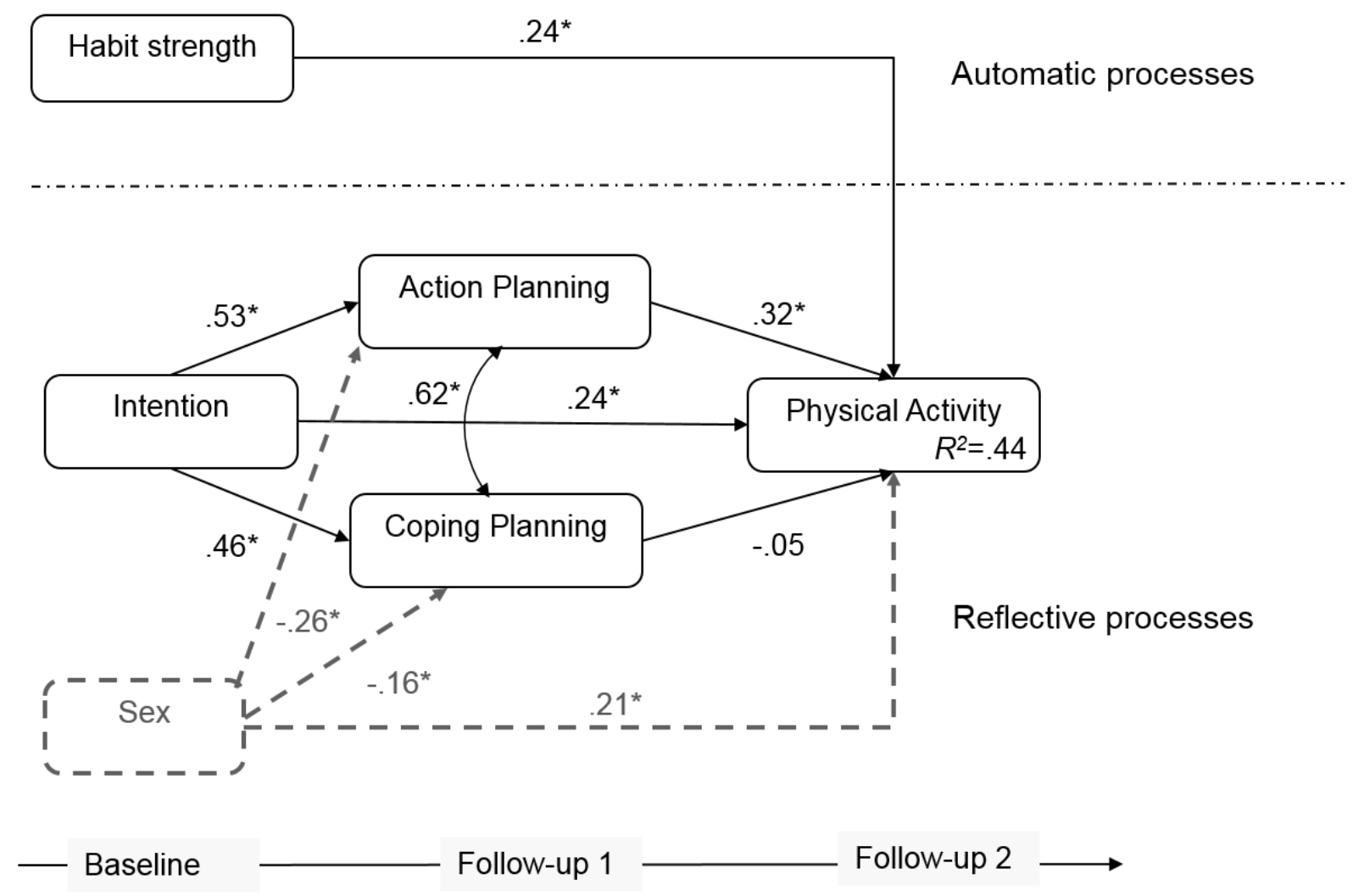

Figure 2. Structured model for predicting older adults' PA $(N=165)$. Fully standardised beta coefficients are reported. Out of the covariates entered (i.e., sex, age, income, and multimorbidity), no significant associations $(p>.05)$ over and above those in the tested model, with an exception of sex, were found. Significance levels were $* * p<0.001$ and $* p<$ 0.05 . 
Table 1.

Older adults and physical activity: descriptive statistics and correlations for latent variables $(N=165)$

\begin{tabular}{|c|c|c|c|c|c|}
\hline & 1 & 2 & 3 & 4 & 5 \\
\hline 1. Intention $\mathrm{T} 1$ & 1.00 & & & & \\
\hline 2. Habit strength $\mathrm{T} 1$ & $0.63 * *$ & 1.00 & & & \\
\hline 3. Action planning $\mathrm{T} 2$ & $0.51 * *$ & $0.33^{*}$ & 1.00 & & \\
\hline 4. Coping planning $\mathrm{T} 2$ & $0.45^{* *}$ & $0.28 *$ & $0.72 * *$ & 1.00 & \\
\hline 5. PA behaviour $\mathrm{T} 3$ & $0.56^{* *}$ & $0.51 * *$ & $0.45^{*}$ & $0.33^{*}$ & 1.00 \\
\hline $\begin{array}{l}\text { Factor loadings for } \\
\text { manifest indicators } \\
\text { within constructs }\end{array}$ & $.96 / .97 / .97$ & $.90 / .85 / .76 / .51$ & $.85 / .89 / .87 / .87$ & $.81 / .84 / .80 / .61$ & $.77 / .88 / .89$ \\
\hline$M^{a}$ & 5.63 & 4.23 & 3.02 & 2.59 & 4.91 \\
\hline$S D^{a}$ & 1.56 & 1.53 & 0.86 & 0.73 & 1.38 \\
\hline Range & $1-7$ & $1-7$ & $1-4$ & $1-4$ & $1-7$ \\
\hline Cronbach's alpha ${ }^{a}$ & .98 & .84 & .92 & .87 & .85 \\
\hline
\end{tabular}

Note. ${ }^{a}$ Manifest scale means, standard deviations, and internal consistency; $* p<.05 ; * * p<.01 . \mathrm{T} 1=$ baseline questionnaire, $\mathrm{T} 2$ = 1-week follow-up, T3 = 2-week follow-up. 